\title{
No sex selection please, we're British
}

\section{John Harris}

$\mathrm{T}$ here is a popular and widely accepted version of the precautionary principle which may be expressed thus: "If you are in a holestop digging!". Tom Baldwin, as Deputy Chair of the Human Fertilisation and Embryology Authority (HFEA), may be excused for rushing to the defence of the indefensible, ${ }^{1}$ the HFEA's sex selection report, ${ }^{2}$ but not surely for recklessly abandoning so prudent a principle. Baldwin has many complaints about my misrepresenting the HFEA and about my supposed elitist contempt for public opinion; readers of this exchange will decide for themselves.

\section{REDRAFTING THE REPORT}

Baldwin begins with a piece of wishful thinking:

\begin{abstract}
Harris objects that in this recommendation "an absurdly high standard of caution is employed", since a theoretical risk is associated with almost all medical procedures. This objection is misplaced: as paragraph 142 of the report indicates, the phrase "theoretical risk" is to be understood here in the light of the earlier discussion of the risks arising from the fact that flow cytometry exposes sperm to laser energy, a procedure which is known to be liable to damage DNA.
\end{abstract}

Paragraph 142 does not make that clear. It does indeed refer back to a set of earlier paragraphs but these give, if anything, an upbeat assessment of the safety of flow cytometry. Paragraph 121 states: "However whilst potentially less intrusive, and with potentially lower risk to the health of patients, flow cytometry ..." (my emphasis). ${ }^{2}$ But even if the overall burden of the report does indicate unresolved fears, the standard is still absurdly high. However, so far from endorsing the report's judgement that flow cytometry has "potentially lower risk to the health of patients", Baldwin now regards the risk of flow cytometry as "serious" :

Since the application of flow cytometry to humans is a new procedure, the risk of human genetic defects caused this way is still only "theoretical"; nonetheless it is serious enough to warrant caution-hence the recommendation that at present flow cytometry should be available only when its use brings clear medical benefits.
If Baldwin's present view is right then we have been seriously misled by the safety assessment in the HFEA report and one is compelled to ask whether it can be consistent with the HFEA's statutory requirement to have regard for the welfare of the child to be born, to permit children to be exposed to risks as serious as this even to secure medical benefits? After all people do not have to have children, and if there is a "serious enough" risk of damage, even medical benefits would probably not justify subjecting children to such a risk. Remember that the children exposed to the risks are not the ones whose health is being protected by the medical benefits. Indeed no child is being protected. The medical benefits result in different healthier children being born. These children would have been healthy in any event (had they been chosen) so do not benefit and the children selected against certainly do not benefit. The benefit is a public health benefit, a eugenic benefit, not a benefit to the child to be born. ${ }^{3}$

\section{WHAT COUNTS AS GOOD EVIDENCE OF PUBLIC ACCEPTANCE}

Next Baldwin complains "it is worth emphasising here that Harris's description of the HFEA inquiry as one which involved only 'respondents to a consultation which necessarily samples a tiny fraction of the population' is misleading." He then proudly notes that the HFEA polled 2000 people and received "641 replies" to its consultation, "including 66 from organisations representing large numbers of people". That makes 2641 responses out of a population of around 60 million. We are not told the "large numbers" that these replies represent, but nothing Baldwin says should give anyone confidence that I am wrong to suggest that these only represent "a tiny fraction of the population". I am sure that scepticism about the legitimacy of proposals to deny choice to the entire community made on the basis of a poll of 2000 people and 66 collective responses from pressure groups, cannot reasonably be described as being "dismissive of public anxieties".

\section{IS SEX SELECTION HARMFUL TO SELECTED CHILDREN}

Since Baldwin knows that there is no empirical evidence available which points to any harms from sex selection per se, nor even any plausible guess as to what that evidence might turn out to be, he turns to the mystical sermonising $^{4}$ of Jürgen Habermas.

Baldwin tells us that ${ }^{1}$ :

Habermas argues that an essential ingredient of our conception of ourselves is that we should be able to regard our embodied character (Leibsein) as a natural phenomenon, and not something which has been, in some respect, deliberately imposed upon us by others, even by our parents. Of course, we must also recognise that in many ways we have been formed by the genes we have inherited from our parents; these genetic predispositions are, however, our bodily inheritance and there is no way in which a human being can be created without some such genetic inheritance. But where a fundamental characteristic such as one's sex has been deliberately selected for things are different ... There is an inescapable alien intrusion into its subjective sense of itself.

Baldwin offers no reason other than the authority of Habermas as to why "an essential ingredient of our conception of ourselves is that we should be able to regard our embodied character (Leibsein) as a natural phenomenon." But again we should be cautious about accepting any of this at face value. Before Darwin, it might have, not implausibly, been asserted that an essential ingredient of our conception of ourselves was that we were created as human beings. Now we know we have evolved in a seamless transition from our common ancestor with chimpanzees, but most of us seem to have adapted well to this dramatic change in Leibsein. The evidence is that human beings are fairly robust and well able to adapt to new conceptions of themselves and their place in the universe. The observations of Galileo and Copernicus were equally, perhaps more, momentous for our conceptions of ourselves and our place in the universe and in the scale of things, but again we seem to have come through.

Although Baldwin accepts the nonidentity of the children who result from different choices, he constantly talks as if this point has not really penetrated very far into his Leibsein. For example it 
"was her parents' choice that their child should be a daughter and in that sense her femininity is indeed imposed on her ..." seems to imply that their child might not have had her femininity imposed on her, that she might have been, and might have preferred to be, a boy. In case Baldwin thinks that this is an unfair characterisation of his words he should ask himself how she might have escaped this fate and avoided this imposition of femininity. We should perhaps recall and emphasise the ways in which sex selection is an excellent precursor of other forms of genetic selection and indeed genetic manipulation and what such choices can and cannot achieve.

\section{SEX SELECTION IS A PARADIGM OF GENETIC MANIPULATION}

Sex selection is an excellent exemplar for discussions of genetic determination because:

(1) Sex is genetically determined.

(2) Gender is harmless, being a boy or a girl is not bad for you.

(3) Selection does not involve shaping the individual in any way, nor can it conceivably make the individual worse off than either $(a)$ she was or (b) she might have been.

The first point needs no further explanation. Let me say something about the claim that gender is harmless. By this I mean simply that it is not harmful to the individual to be a man or a woman. Men and women have existed since humans have and although there have been severe power imbalances between the two genders for most of human history the damage that this has caused is contingent, not a necessary part of maleness or femaleness. If gender is what I call a "morally neutral trait" then it cannot be morally wrong to be a man or a woman and so it cannot be morally wrong to create a man or a woman. The only remaining question is whether it can be morally wrong to create a man rather than a woman or vice versa. $^{5}$

The third element is very important. There is no complaint the "victim" of sex selection can make because for her there was no alternative but never to have existed. "She" could not have been a boy. This is because the boy that might have been selected or created instead of her would not have been "her" only with a different sex. It would not have been a case of sex reallocation. It would simply have involved the creation of an entirely different person.

Although this is hardly ever noticed the same is true for any significant genetic manipulation that might be made to an embryo or indeed to the gametes prior to conception, if this ever becomes possible. So complaints that parents who would use sex selection are attempting to shape or mould their child are simply incoherent. They may of course be choosing what sorts of children there will be, but none of those children have any legitimate or even coherent complaint, for they could not have had an alternative life free of such externally imposed choices.

THE DEMOCRATIC PRESUMPTION Finally we must turn to the HFEA's rejection of what I have called the "democratic presumption". And this is down to the HFEA and not the Human Fertilisation and Embryology Act 1990. Introducing his discussion of this Baldwin says ${ }^{1}$ :

In the final part of his paper Harris criticises the way in which the HFEA, having given a "firm and consistent statement" of the liberal presumption that the state should not intervene in family life except to prevent serious harm, abandons this principle in the light of the public hostility to sex selection revealed by its consultation. This is the most important of his criticisms and in responding to it I should acknowledge that the discussion of this matter in the HFEA report is not as full as, in retrospect, was desirable. ... In doing so even he acknowledges that "there is no widespread agreement as to the nature and scope of this right" $^{\prime \prime}$ so, on the face of it, even he should accept that he cannot just invoke this right in order to legitimate sex selection ... this area of reproductive liberty is not fundamental to liberal democracy, as Harris ludicrously maintains ...

Although we both agree that the force of this presumption is really the key issue, Baldwin, I am sorry to say, completely misunderstands what the democratic presumption entails.

First, I did not "invoke" any right of reproductive choice in order to legitimate sex selection. I set out the arguments for such a right to show that claims in this area were not simply idle preferences; however, nothing in my argument turns on establishing or even accepting reproductive liberty as a fundamental right. The democratic presumption does not protect only established rights. Moreover it is difficult to understand how Baldwin can claim with a straight face that I "ludicrously" maintain that this area of reproductive liberty is fundamental to liberal democracy. I maintain no such thing. I invoke the democratic presumption exactly in the way the HFEA report does (at paragraph 132 ) $^{2}$ as a presumption that we all accept and that must somehow be met, not evaded or, in the case of the HFEA reformulated so that it is emptied of content.

The point is not whether or not this particular dimension of reproductive liberty is fundamental to liberal democracy; that I concede is hardly likely. But that does not mean that the denial of reproductive liberty or this dimension of it is not fundamental to liberal democracy, nor that it is ludicrous to suggest it is. What is fundamental to liberal democracy is that the liberty of citizens should not be abridged unless good and sufficient cause can be shown as to why this is required. This is true whether the liberty asserted is the freedom to drink tea or the freedom to reproduce. When, for example, we say that "due process of law" is a principle of liberal democracies, that it protects all, we are not saying that the alleged commission of any particular offence goes to the heart of liberal democracy, nor that the wrongful or even the unsound conviction of any individual threatens democracy. We are saying that the institution of due process is essential and that deliberately setting it aside (as sometimes in terrorism cases) requires the weightiest justification.

As I argued in my original paper, even idle preferences command respect and their denial requires justification. But serious moral claims require the greatest respect and the weightiest reasons must justify their denial, even where those claims are just that, "claims" and not established moral rights. It is not the particular liberty that has to be important, what is important is that the burden of proof is on those who would curtail liberty. Since the HFEA report invokes the democratic presumption in precisely this context and in this way Baldwin's comments must be taken as an attempted criticism of the HFEA report. If my invocation of this principle is ludicrous then so is that of the HFEA, if not then the HFEA has me to thank for defending it against one criticism from the Deputy Chair which is way off target.

If as Baldwin states, there are powerful arguments on both sides then the presumption must be in favour of liberty. However I did argue, and still maintain, that reproduction clearly is an important liberty by any standards and while maybe not itself be constitutive of liberal democracy it is by any reckoning of an importance which requires serious engagement if it is to be set aside. In this it may be different from drinking tea. I 
also argued and nothing that Baldwin has produced casts any doubt on this whatsoever, that there are no powerful arguments against the exercise of this liberty by sex selection. No evidence of harm was produced by the HFEA (only evidence that some people don't like the idea of it) and Baldwin now concedes the absence of any evidence by calling in aid the mystical, and in so far as they are coherent, doubtful assertions of Habermas.

\section{BEYOND REASON}

Indeed, when Baldwin claims of his invocation of Habermas: "In drawing on Habermas in this way my aim has been to show that the objection to the exercise of reproductive liberty in this area is not just a matter of disputable empirical harms. The issue goes much deeper ..." he shows that he has given up on evidence and argument altogether. Baldwin is taking the "argument" beyond disputable harms because he knows not only that such harms have not been and cannot be established, he knows that there is no credible reason to think that any serious harms might eventuate. Harbermas does not simply take the argument "deeper", he takes the debate to a depth that neither rationality nor evidence can reach. Safe in the impenetrable murk that pervades such depths Baldwin can assert what he likes, knowing that because the fears that there find expression are not supported by evidence or by argument or by reason they are truly unreasonable. As Jonathan Swift is believed to have said, "it is hopeless to reason a man out of something that he has not been reasoned into".

Given an absence of evidence and a very low probability of harm, it is surely perplexing that the HFEA did not take the cautious but democratic step of saying-yes you can do this but initially it should be regulated which will involve contributing to research studies that will evaluate the impact of this new technology. ${ }^{6}$

\section{A MODEST PROPOSAL}

My own proposal, which I first published in 1998, ${ }^{5}$ would be that a society like ours, of about 60 million people, should perhaps begin with cautious regulation. We surely could "afford" to licence, say one million, procedures for sex selection over a 10 year period with options to revise the policy if severe imbalance seemed likely or if unforeseen harms began to emerge. We could then see what patterns of selection and motivation emerged and whether any significant problems were caused to individuals or to society. Even if all choices went one way, the imbalance created would be relatively small before detection, and a halt could be called if this seemed justifiable. I doubt that the places allocated on such a programme would be taken up (it would of course be self-financing and would not be part of the public healthcare system). It must be remembered that those who opted for sex selection would (with current technology) have to be very circumspect about their procreation and use assisted reproduction or the various methods so well described in the HFEA's report. This would not, I guess, be wildly attractive or indeed particularly reliable. For the foreseeable future the take-up will also by limited by the availability of clinics offering the service. In any event, the way forward for a tolerant society respectful of autonomy, and mindful of the democratic presumption, would surely be not to rush to prohibitive legislation, but rather to licence the activity with regular monitoring and follow up studies and see whether anything so terrible that it required prohibitive legislation emerged.

J Med Ethics 2005;31:286-288.

doi: 10.1136/jme.2004.008870

Correspondence to: John Harris, Institute of Medicine, Law and Bioethics, School of Law, Williamson Building, University of Manchester, Oxford Road, Manchester M13 9PL;

john.m.harris@man.ac.uk

\section{REFERENCES}

1 Baldwin T. Reproductive liberty and elitis contempt: reply to John Harris. J Med Ethics 2005;31:288-90.

2 Human Fertilisation and Embryology Authority. Sex selection: options for regulation. A report on the HFEA's 2002-03 review of sex selection including a discussion of legislative and regulatory options. London: HFEA, 2003

3 Eugenics will appear problematic only to those who think there is a radical and important distinction between concern for the health and welfare of future people and concern for the health and welfare of existing people.

4 For the second time in this exchange I call in aid WS Gilbert. This time The Mikado Act II. WS Gilbert. The Savoy Operas. London: Macmillan and Co, 1956

5 See: John Harris. Rights and Reproductive Choice. In: John Harris, Søren Holm, eds. The Future of Human Reproduction: Choice and Regulation. Oxford University Press, 1998:5-37.

6 I am grateful to Theresa Marteau for this suggestion.

\section{Reproductive liberty and elitist contempt: reply to John Harris}

\section{T Baldwin}

$n$ "Sex selection and regulated hatred"1 John Harris launches a vehement critique of the Human Fertilisation and Embryology Authority's (HFEA) recent report Sex Selection: options for regulation, raising several issues that merit discussion.

He begins by complaining about the recommendation that because of the theoretical risk associated with the use of flow cytometry as a method of sperm sorting, its use should be restricted for the moment to cases in which a clear medical benefit is to be gained from its use. Harris objects that in this recommendation "an absurdly high standard of caution is employed", since a theoretical risk is associated with almost all medical procedures. This objection is misplaced: as paragraph 142 of the report indicates, the phrase "theoretical risk" is to be understood here in the light of the earlier discussion of the risks arising from the fact that flow cytometry exposes sperm to laser energy, a procedure which is known to be liable to damage DNA. Since the application of flow cytometry to humans is a new procedure, the risk of human genetic defects caused this way is still only "theoretical"; nonetheless it is serious enough to warrant cautionhence the recommendation that at present flow cytometry should be available only when its use brings clear medical benefits. The HFEA has recently been criticised by some for not being cautious enough when permitting the use of intracytoplasmic sperm injection (ICSI) even though in that case there are clear medical benefits from its use. It is extraordinary that Harris should now criticise the HFEA for not throwing caution to the winds concerning flow cytometry. 
Harris' next point concerns the justification for this suggestion that preimplantation sex selection should be available only where it is undertaken for medical reasons. The obvious way to justify this would appear to be on the ground that, because of the risks involved, it is only where there are clear medical benefits that the procedure is in the interest of a child thus created. As Harris observes, however, this argument would be a mistake; because these procedures determine who exists one cannot sensibly argue that it is only where medical benefits are to be gained that their use is in the interest of the person(s) thus created. Harris, however, seems determined to attribute this unsatisfactory line of thought to the HFEA: he writes "The only way to sustain the idea that seems to be in the heads of the members of the HFEA is to argue that although exposed to greater risk, such risks are in the interests of the child exposed to them because it is that child's only chance of existence". This is mystifying: there is nothing in the HFEA's report to warrant imputing this idea to the HFEA. But one thing which seems to have guided Harris here is the famous clause 13(5) of the Human Fertilisation and Embryology (HFE) Act 1990 which requires the HFEA to ensure that, in the provision of "treatment services" "account has been taken of the welfare of the child who may be born as a result of the treatment". For Harris says that he assumes that this clause has to be interpreted in such a way that "the child" whose welfare is at issue is "the particular child calculated to be the product of the combination of choices and technology used"; and once this interpretation is in place, it may seem to follow that sex selection procedures can only be allowed by the HFEA where they advance the welfare of "the particular child ...".

The first thing to note here is that if Harris's assumption here is right, it is the HFE Act, and, not the HFEA itself, which imposes the requirement that sex selection for medical reasons be justified as in the interest of "the particular child" etc. The second thing to say, however, is that Harris's assumption is unnecessary; the requirement to take account of the welfare of the child can be understood as a general requirement to take account of the welfare of any children who may be born as a result of the treatment. On this interpretation sex selection for medical reasons can then be justified under the Act by the fact that, when judged by the standards of the welfare of the children who may be born, the result where sex selection is used to avoid a sex linked serious condition is much better than where it is not used, despite the risks involved. ${ }^{2}$ Towards the end of his discussion of this issue Harris himself seems to accept this: he writes "Now of course there is a sense in which the HFEA is quite right. The Authority wants to say that for parents at risk of producing a child with a sex linked disorder there is an important therapeutic advantage in sex selection". Having conceded this, however, Harris argues that if this is the HFEA position, then, in all consistency, it should allow sex selection for other reasons as well. But there is no such implication. The welfare of the children who may be born is a consideration which justifies sex selection for medical reasons. But where sex selection is to be used when there is no risk of serious inherited sex linked conditions and is instead intended primarily to satisfy parental preferences, the appeal to the welfare of the children who may be born cannot be invoked as a justification for it. Of course, more argument is required to show that parental preference is not a sufficient justification. But in order to rebut the accusation of inconsistency that is not to the point. So Harris's claim that there is an inconsistency in the HFEA's judgements on this issue is entirely without foundation.

In the final part of his paper Harris criticises the way in which the HFEA, having given a "firm and consistent statement" of the liberal presumption that the state should not intervene in family life except to prevent serious harm, abandons this principle in the light of the public hostility to sex selection revealed by its consultation. This is the most important of his criticisms and in responding to it I should acknowledge that the discussion of this matter in the HFEA report is not as full as, in retrospect, was desirable. Harris begins by setting out some statements of the right to reproductive liberty from Robertson, Dworkin, and Savalescu. In doing so even he acknowledges that "there is no widespread agreement as to the nature and scope of this right"; so, on the face of it, even he should accept that he cannot just invoke this right in order to legitimate sex selection, since this is precisely an area in which there is no agreement concerning its scope. Indeed, if anything, the opposite is the case: the HFEA's inquiries revealed very general agreement that sex selection for nonmedical reasons should not be permitted. Of course, it is disputable what weight should be attached to this finding, and I shall return to this question. But it is worth emphasising here that Harris's description of the HFEA inquiry as one which involved only "respondents to a consultation which necessarily samples a tiny fraction of the population" is misleading. As the report states, the HFEA's inquiry had three strands: (a) several focus groups were gathered in different parts of the country (London, Edinburgh, Belfast, Cardiff, and Birmingham), involving people of different ages and from different social classes and ethnic backgrounds; $(b)$ the HFEA commissioned a MORI poll of over 2000 adults, chosen by MORI to be as representative as possible from all across the country; (c) the HFEA itself produced a consultation document which was sent out to interested groups of all kinds and made available on the web; this attracted 641 replies, including 66 from organisations representing large numbers of people. And what were the results? Some details are in our report; more can be found in the appendices available from the HFEA's website (www.hfea.gov.uk/ Home). But, in brief, all three methods revealed deep opposition to sex selection, except where it was justifiable on medical grounds; and even that justification was often rejected. I myself was surprised by the extent of this opposition, which was by no means confined to religious groups. Even where the HFEA's critics reject its recommendation they should at least accept this finding; it is wishful thinking to suppose otherwise.

It was certainly not the HFEA's view, however, that this finding was by itself decisive; this claim is explicitly rejected in the report (in paragraph 147). But it did play an important role in our deliberations. Before explaining this role, however, I need to return to the issue of "reproductive liberty". This liberty, like any other, is constrained by the requirement that its exercise should not pose a risk of harm to others, in particular to the children thus conceived; and it is worth noting that $\mathrm{J} \mathrm{S}$ Mill remarks that for this reason the application of the principle of liberty to family life is not straightforward ${ }^{3}$ :

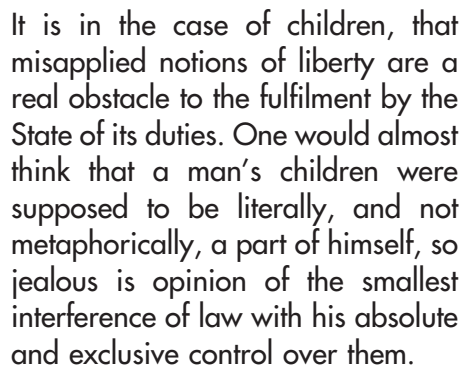

Thus it is here that most critics of unrestricted sex selection seek to make their case, arguing that where sex selection is undertaken without medical 
justification there is a likelihood of harm to children whose sex is thus determined. ${ }^{4}$ Harris, however, dismisses these arguments as mere "prejudices", and, having thus dismissed them, he criticises the HFEA for invoking the public support for them as a reason for suggesting that sex selection should be restricted to cases where there is a serious medical reason for it.

But is Harris right to be so dismissive of public anxieties concerning this issue? The practice of sex selection for non-medical reasons would bring something altogether new to human reproduction, namely the possibility for parents to make a positive selection, for non-medical reasons, of the kind of child they are to have. Sex selection for medical reasons is typically negative: it is undertaken to enable parents to avoid having a child with a sex linked serious condition. ${ }^{5}$ The importance of the switch from negative to positive, and from the medical to the non-medical, is that it brings into focus the anxieties which attach to the term "designer baby". Although there is no practical necessity which connects sex selection to selection for other characteristics which parents might seek, there are no good reasons for treating sex selection as a unique case. So the issue of sex selection has great symbolic importance in this context. ${ }^{6}$

A common theme of many of the responses the HFEA received was that the relationship between parents and their children would be distorted if parents were able to determine the sex of their children. Sometimes this point was expressed as the claim that sex selection would threaten the child's "otherness", its independence, and this claim points to a concern that motivated much of the public opposition to sex selection. The best elucidation of it that I know of is provided by Jürgen Habermas in his book The Future of Human Nature. ${ }^{7}$ Habermas argues that an essential ingredient of our conception of ourselves is that we should be able to regard our embodied character (Leibsein) as a natural phenomenon, and not something which has been, in some respect, deliberately imposed upon us by others, even by our parents. Of course, we must also recognise that in many ways we have been formed by the genes we have inherited from our parents; these genetic predispositions are, however, our bodily inheritance and there is no way in which a human being can be created without some such genetic inheritance. But where a fundamental characteristic such as one's sex has been deliberately selected for things are different: a central aspect of the character of such a child has been deliberately chosen by the child's parents-that the child be a girl or a boy. Unless its manner of conception is kept secret, which is itself ethically objectionable, the child will come to learn that it was deliberately created in a way which ensures that it is a certain kind of person-in a way which is so intimate and bodily that it cannot repudiate this mode of being, however much it might wish to do so. Thus there is an inescapable but alien intrusion into its subjective sense of itself.

One might well object that if this argument works at all it proves too much. For does it not imply that there is something objectionable about sex selection for medical reasons? Habermas, if I understand him correctly, does indeed draw this conclusion. But I think the implication can be rejected; for in such a case a daughter can internalise her parents' wish that they should avoid having a child with a serious disease (for example TaySachs), and accept that as a result she had to be a girl, without feeling thereby that she was selected because her parents had some positive preference for girls for their own sake. It was her parents' choice that their child should be a daughter and in that sense her femininity is indeed imposed on her, but only as the consequence of an understandable negative choice. So she need not experience her feminine bodily character as the result of someone else's positive design.

In drawing on Habermas in this way my aim has been to show that the objection to the exercise of reproductive liberty in this area is not just a matter of disputable empirical harms. The issue goes much deeper and concerns the child's subjective sense of itself. Of course this too remains disputable. But when the matter is addressed on this level it is much less clear where the balance of argument lies between the proponents of reproductive liberty and the defenders of the independence of the child, and there was in fact no consensus among the members of the HFEA on this matter. Instead there was agreement that this is an issue where there are powerful arguments on both sides of the case, but also that neither side can seriously maintain that immediate serious harm is in prospect: this area of reproductive liberty is not fundamental to liberal democracy, as Harris ludicrously maintains; equally its exercise is not comparable to child abuse. Hence, with all the evidence described earlier which showed public opinion very largely on one side of the argument, the HFEA accepted that it was reasonable that public policy should be guided by this public consensus until the argument is further resolved. To do this was not to lamely capitulate to the "tyranny of the majority" in the way that Harris alleges; for the proponents of reproductive liberty among the HFEA did not share his elitist contempt for the grounds of public opposition to it as mere prejudice. We all felt that there is here a difficult judgement to be made as to which value should have priorityreproductive liberty or protection for the independence of the child; and since we found no way of resolving this issue dialectically, we recommended that public policy should for the moment be guided by the value which commands the support of the clear majority of the public. $^{8}$

\section{J Med Ethics 2005;31:288-290.}

doi: 10.1136/jme.2004.008045

\section{Correspondence to: T Baldwin;} trb2@york.ac.uk

\section{REFERENCES}

1 Harris J. Sex selection and regulated hatred. J Med Ethics 2005;31:291-4.

2 There are further complexities concerning the use of human leucocyte antigen (HLA) tissue typing to create saviour siblings, but they are not relevant here.

3 Mill JS. On liberty. In: Collini S, ed. On Liberty and other writings. Cambridge: Cambridge University Press, 1989:p. 105 (ch 5).

4 Some also argue that there is a significant risk of fathers coercing their partners into unwanted sex selection procedures.

5 The exception here of course is the use of HLA tissue typing to create a saviour sibling

6 So what, Harris will say: What is wrong with the ability to create a superman? See his book Wonderwoman and Superman: the ethics of human biotechnology. Oxford: Oxford University Press, 1992

7 Habermas J. The Future of Human Nature. Cambridge: Polity, 2003.

8 At the last minute I was shown the text of Harris's rejoinder to me On most of the points he makes I have nothing to add to what I say here, and I do not think anything needs to be added. But there is one point worth taking further. It is agreed between us that because the selection of an embryo determines the identity of any child born as a result, selecting a female embryo (for example) is not choosing, for a given child, that she be female. Harris seems to think that I have failed to appreciate the significance of this point, and that by itself it undermines the Habermasian argument I discuss. This claim is certainly mistaken. Where parents use embryo selection to have a daughter they choose that their child be feminine. Thus once their daughter learns of this her sense of her own identity includes the thought that her own femininity is the result of her parent's choice that they should have a daughter (though not, of course, a choice that she should be feminine). Whether or not this thought brings with it, as Habermas maintains, a potentially damaging alienation of her sense of identity is another matter. All I want to make clear here is that the thought which forms the starting point of Habermas' argument is not inherently confused in the way that Harris suggests. 


\title{
Sex selection and regulated hatred
}

\author{
John Harris
}

Sex selection: options for regulation. A report on the HFEA's 2002-03 review of sex selection
including a discussion of legislative and regulatory options. A critique

have titled this paper discussing sex selection and the recent report by the Human Fertilisation and Embryology Authority (HFEA) " "Sex selection and regulated hatred" after the famous essay on Jane Austen by DW Harding. ${ }^{2}$ In that essay Harding argues that Austen's work is best understood as subtly expressing Austen's hatred for the small-minded and petty bourgeois world, full of prejudices and conceits she describes, a hatred regulated by her ironic and deft prose. The HFEA report embodies a sort of mirror image of Harding's insight. In the report, the opinions emerging from the consultation exercise, which, unsupported by evidence or valid arguments are impossible to distinguish from prejudices, are given formal approval and proposed regulation by a government appointed body set up with the responsibility to provide expert leadership. The leadership in fact exemplified in this report owes much to the legendary Duke of Plaza Toro, so faithfully and tellingly recounted by W S Gilbert. ${ }^{3}$

In her introduction to the HFEA's report Suzi Leather, Chair of the HFEA, remarks:

I consider that our conclusions and the advice contained in this report represent an informed, balanced and proportionate response to the very complex issues raised by sex selection and I hope it will stand as a principle point of reference for all those-Government, professionals and the interested public-who will be involved in taking the debate forward.

I suppose that by stretching a point one might call this report "informed"; balanced and proportionate it isn't. However, while undoubtedly informed, it is informed largely by the results of a public consultation, the "hostility" of which to sex selection is manifest and even explicitly acknowledged in those terms by the HFEA, and is accepted at face value. But more importantly the HFEA's report is hopelessly inconsistent and, in the rare cases in which arguments appear, very poorly argued. The form of the document is also revealing.

\section{Abstract}

This paper argues that the HFEA's recent report on sex selection abdicates its responsibility to give its own authentic advice on the matters within its remit, that it accepts arguments and conclusions that are implausible on the face of it and where they depend on empirical claims, produces no empirical evidence whatsoever, but relies on reckless speculation as to what the "facts" are likely to be. Finally, having committed itself to what I call the "democratic presumption", that human freedom will not be constrained unless very good and powerful reasons can be produced to justify such infringement of liberty, the HFEA simply reformulates the democratic presumption as saying the opposite-namely that freedom may only be exercised if powerful justifications are produced for any exercise of liberty.

The bulk of it - that is, Chapters 1-4 (of six chapters) concerns background, overview of the reportage of commissioned research, and public attitudes. Virtually the whole of the burden of establishing the report's conclusions is permitted to, and clearly does, emerge from the public consultation. Whether or not the public consultation was informative of the debate it was in effect determinative of the conclusions that the HFEA reached. After these first four chapters the report moves swiftly to its conclusions without any demonstration of balancing or considering the relevant arguments. The ethics literature review, for example, is highly selective failing to refer to many key texts.

\section{AN EXAMINATION OF THE REPORT'S CONCLUSIONS}

As is now well known, the HFEA has come out strongly against all but strictly therapeutic uses of sex selection; and by "therapeutic" is meant uses which prevent the passing on of sex linked disorders. Let us start with the inconsistency involved in this exception. The first thing to note is that the HFEA was very cautious. It ruled out one method of sex selection, namely flow cytometry, because "It is not possible to discount a theoretical risk to health with the use of this technique". Of course one will never discount risks if this absurdly high standard of caution is employed. Such a standard would rule out the benefits of almost all medical procedures, because there is always a theoretical risk, if not an actual risk, however slight. It may be that this method of sex selection should not be used on safety grounds, not because there is "a theoretical risk to health", but surely because there is a real and significant risk.

The HFEA then goes on to consider so called "gradient methods" of sex selection and notes that "there is no reason to suspect that gradient methods pose a significant risk to the health of offspring". We should note in passing, of course, that even this certificate of risk free health given by the HFEA would fail its previously employed rigorous test, namely that "it is not possible to discount a theoretical risk to health". Since it is never possible to discount such a risk, if this is an objection it applies to gradient methods as powerfully as it does to flow cytometry ... however, let that pass. What is clear is that the HFEA regards even minimal risks to the health of resulting children which may flow from risks inherent in the methods of sex selection (rather than any social or psychological outcomes) as decisive in rejecting sex selection except where it would be used to rule out the inheritance of sex linked disorders. Now this is a startling conclusion, since at paragraph 129 the HFEA states: "The risk of passing on a serious sex-linked genetic condition is a good and, other things being equal, sufficient reason for prospective parents to be offered the options of sex selection". Note that the risks inherent in the procedures of sex selection will still be present where the purpose is to eliminate sex linked disorders, and so the HFEA's argument seems to be that it is reasonable for parents to expose their future children to risks to their health because the alternative for these parents 
is to expose different children ${ }^{4}$ to greater risks. The HFEA avoids consideration of a third alternative in this context, which is that parents do not need to expose children to significant risks at all. They can use embryo selection or abstain from reproduction. However, since the avoidance of greater risks to different children is not something that can benefit the particular children who will be born as a result of the sex selection, it surely cannot justify exposing these children to risk if the risks are unacceptably high. To talk of greater risks to different children is slightly problematic. If no sex selection is used either boys or girls may result. Sex selection to eliminate sex linked disorders usually tries to eliminate males since they are more likely to be affected. The interesting question is who benefits? The class of children saved from "risk" by sex selection are at risk of being born with a serious disease. But in some cases such an existence may still be preferable to non-existence. So they may be saved from the risk of disease at a greater (almost 100\%) risk of non-existence. In such a case it might be argued that only the parents and society benefit from this risk avoidance strategy and that the welfare of the child to be born has no place in the calculation.

Compare using one child as a bone marrow or even a kidney donor for a sibling. This would equally be a case in which a child would be required to run risks rather than expose a different child to greater dangers, but I doubt that would be thought obviously consistent with arguments requiring the welfare of the child concerned to be taken into account. $^{5}$ I assume that the welfare of "the child who may be born" refers to the welfare of the particular child calculated to be the product of the combination of choices and technology used. The only possible alternative understanding of the meaning of the phrase "welfare of the child to be born", sees it as requiring a eugenic programme for reproduction aimed at producing the best of all possible children in the circumstances. This would be an altogether different project, and one, I would suggest, that is even further from the project of the framers of the Human Fertilisation and Embryology Act or those who voted for it.

The only way to sustain the idea that seems to be in the heads of the members of the HFEA is to argue that although exposed to greater risk, such risks are in the interests of the child exposed to them because it is that child's only chance of existence.

It is as if the future children have been offered a bargain: "Here's the deal, you have a chance of coming into existence but only if you accept greater than normal risks—-take it or leave it!". A rational embryo or would-be embryo would take the deal, because the alternative is non-existence. This is the only appeal which makes sense in terms of the interests of "the children who will be born"; but I doubt if the HFEA would wish to endorse it because then it would have to do so in the simple sex selection case. $^{6}$

We should note that this way of thinking of things does not involve the attribution of interests to non-existent beings (although I see nothing in principle wrong with such an attribution). We may translate the hypothetical deal I have described as if it were put post facto to existing children. We say to them: "Ok you exist, but at greater risk than would have been required for other kids to exist. Was it worth it? Was it a good deal?". I imagine they would answer "Yes" unless life for them was not worth living.

Now of course there is a sense in which the HFEA is quite right. The Authority wants to say that for parents at risk of producing a child with a sex linked disorder there is an important therapeutic advantage in sex selection. Given that they are going to procreate it enables them to have a child with less risk of malformation or disease than available alternatives. For this choice to be ethical we have to judge the risk involved in the sex selection procedure so small as to justify it in terms of dangers to the resulting child, unless we appeal to the argument that asks what a rational embryo would choose-the so called "non-identity" argument. This argument, invented by Derek Parfit, shows that reproductive choices which select the child to be born cannot harm that child or do other than promote the child's welfare unless they create a child with a life not worth living. ${ }^{7}$ Remember in the case of a genetic link with sex linked disorder the parents get a child without having to risk having a child with a sex linked disorder, which by hypothesis they do not want. But that is the same in the simple sex preference case. In that case too sex selection gives the parents a chance to have a child, who is free of a condition (male of female), which the parents do not want. Of course the parents in one case have a more pressing or serious justification according to some. But this too is a matter of judgement of a considerably problematic nature, for in neither case do the parents have to procreate. They can abstain. The alleged case of "necessity" is predicated upon the procreative imperative. But a lot more argument is needed to show that the imperative involves mere procreation as opposed to chosen procreation. Which brings us to the HFEA's other arguments concerning choice and to reproductive liberty and the democratic presumption.

\section{REPRODUCTIVE CHOICE AND THE DEMOCRATIC PRESUMPTION}

At paragraph 132, the HFEA sets out and commits itself to what may be called the democratic or the liberal presumption; the Authority expresses it thus:

The main argument against prohibiting sex selection for non medical reasons is that it concerns that most intimate aspect of family life, the decision to have children. This is an area of private life in which people are generally best left to make their own choices and in which the State should intervene only to prevent the occurrence of serious harms, and only where this intervention is nonintrusive and likely to be effective.

This is a firm and consistent statement of one of the presumptions of liberal democracies; that the freedom of citizens should not be interfered with unless good and sufficient justifications can be produced for so doing. The presumption is that citizens should be free to make their own choices in the light of their own values, whether or not these choices and values are acceptable to the majority. In this report, however, the HFEA simply surrenders to the hostility to sex selection of a majority (not of citizens, but of respondents to a consultation which necessarily samples a tiny fraction of the population) and gives, in the end, no weight to this important liberal principle and presumption underlying all democratic societies. We will examine the rather impoverished reasons why the HFEA has abandoned democratic principles but before doing so we need to consider substance of the idea so often now referred to as "reproductive liberty" or "procreative autonomy".

\section{REPRODUCTIVE LIBERTY}

When people express their choices about procreation they are claiming an ancient, if only recently firmly established, example of what may be termed a "fundamental right". This right or entitlement is found in all the principle conventions or declarations of human rights. Sometimes it is expressed as the right to marry and found a family, sometimes as the right to privacy and the right to respect for family life (see the United Nations Universal Declaration of Human Rights Article 16, 1978, the European Convention on Human Rights, 
Article 8 and Article 12, 1953, and the International Covenant of Civil and Political Rights Article 23, 1976). This right or entitlement is often discussed in terms of "reproductive liberty" or "procreative autonomy".

The right or entitlement to reproductive liberty has a number of different sources and justifications. Some see it as derived from the right to reproduce per se, others as derivative of other important rights or freedoms. Certainly there is no widespread agreement as to the nature and scope of this right; however, it is clear that it must apply to more than conventional sexual reproduction and that it includes a range of the values and liberties which normal sexual reproduction embodies or subserves. For example, John Robertson outlining his understanding of this right suggests ${ }^{8}$ : "The moral right to reproduce is respected because of the centrality of reproduction to personal identity, meaning and dignity. This importance makes the liberty to procreate an important moral right, both for an ethic of individual autonomy and for the ethics of community or family that view the purpose of marriage and sexual union as the reproduction and rearing of offspring. Because of this importance the right to reproduce is widely recognised as a prima facie moral right that cannot be limited except for very good reason."

Ronald Dworkin has defined reproductive liberty or procreative autonomy as "a right to control their own role in procreation unless the state has a compelling reason for denying them that control". "The right of procreative autonomy has an important place ... in Western political culture more generally. The most important feature of that culture is a belief in individual human dignity: that people have the moral right-and the moral responsibility-to confront the most fundamental questions about the meaning and value of their own lives for themselves, answering to their own consciences and convictions ... The principle of procreative autonomy, in a broad sense, is embedded in any genuinely democratic culture." ${ }^{\prime \prime}$

Julian Savulescu gives a classical twist to arguments about reproductive liberty suggesting that the core idea derives from an element in John Stuart Mill's defence of liberty, which highlights the crucial role played by the freedom to experiment. Savulescu sets the idea out thus ${ }^{10}$ : "Reproduction should be about having children who have the best prospects. But to discover what are the best prospects we must give individual couples the freedom to act on their own value judgement of what life constitutes a life of prospect.
'Experiments in reproduction' are as important as 'experiments in living' as long as they don't harm the children who are produced. For this reason, reproductive freedom is important. It is easy to grant people the freedom to do what is agreeable to us; freedom is important only when it is the freedom for people to do what is disagreeable to others."

Arguably Robertson's, Dworkin's, and Savulescu's accounts all centre on what I believe to be the key idea of reproductive liberty, namely respect for autonomy and for the values which underlie the importance attached to procreation. These values see procreation and founding a family as involving the freedom to choose one's own lifestyle and express, through actions as well as through words, the deeply held beliefs and the morality which families share and seek to pass on to future generations. ${ }^{11}$

Given that the freedom to pass on one's genes is widely perceived to be an important value, it is natural to see this freedom as a plausible dimension of reproductive liberty, not least because so many people and agencies have been attracted by the idea of the special nature of genes and have linked the procreative imperative to the genetic imperative. Whether or not this suggestion is ultimately persuasive, it is surely not possible to dismiss the choices about reproduction and access to the relevant technologies which constitute the point of claiming reproductive liberty as a simple and idle exercise of preference. Reproductive choices, whether or not they prove to be protected by a right to procreative liberty or autonomy, have without doubt a claim to be taken seriously as moral claims. As such they may not simply be dismissed wherever and whenever a voting majority can be assembled against them. Those who seek to deny the moral claims of others (as opposed, possibly, to the exercise of their idle preferences) must show good and sufficient cause. We do not, to paraphrase Ronald Dworkin, allow the majority to determine what religion others are permitted to follow because we rightly regard such matters as issues of personal liberty and fundamental rights.

\section{THE HFEA AND DEMOCRATIC PRINCIPLES ${ }^{12}$}

In the paragraphs following paragraph 132 the HFEA rehearses many of the considerations that were adduced in the public consultation and it is not clear always whether it is endorsing these or merely repeating them. The HFEA rightly dismisses considerations that sex selection may produce a gender imbalance and relies in effect on the following few, and I believe totally inadequate, considerations.

The first is set out in paragraph 139 where it states "In our view the most persuasive arguments for restricting access to sex selection technologies, beside the potential health risks involved, are related to the welfare of the children and families concerned". The HFEA then glosses this concern for children by noting that, "Children selected for their sex alone may be in some way psychologically damaged by the knowledge that they had been selected in this way as embryos". This is a very tendentious and unwarranted way of putting the point. The HFEA produces no evidence, nor indeed could it produce any evidence, that children would be selected for their sex alone. This is the point which derives from Kantian ethics, that individuals must be treated as ends in themselves and not as mere means. However, it is very difficult to find evidence or even persuasive anecdotes that if people are treated as means they are treated as mere means or exclusively as means. It is very unlikely that children selected for their sex would be selected solely for their sex. Indeed it is difficult to understand what that might mean. Also the idea that even if this were the case, they would be so unloved and treated so unacceptably badly that it would cause psychological damage is a piece of reckless speculation for which no evidence is produced and indeed no evidence could be produced. The HFEA then repeats (or is it endorses?) two other considerations, namely "That such children would be treated prejudicially by their parents and that parents would try to mould them to fulfil their (the parents) expectations. Others saw a potential for existing children in the family to be neglected by their parents at the expense of sex selected children." Well, these so called dangers may be theoretically possible, but they are hardly realistic. Suffice it to say that for these highly speculative and fanciful dangers (for which no evidence is produced and indeed for which so far as I am aware no evidence exists) to count against the powerful formulation of the liberal imperative would be effectively to deny that imperative any weight or role at all; and indeed this is precisely what the HFEA has done, because in paragraph 147, which is the final statement of the HFEA's justifications for rejecting sex selection and indeed for proposing legislation against it, it states the following (my italics):

In reaching a decision we have been particularly influenced by the considerations set out above relating to 
the possible effects of sex selection for non medical reasons on the welfare of children born as a result, and by the quantity of strength of views from the representative sample polled by MORI and the force of opinions expressed by response to our consultation these show that there is very wide-spread hostility to the use of sex selection for non medical reasons. By itself this finding is not decisive; the fact that a proposed policy is widely held to be unacceptable does not show that it is wrong. But there would need to be substantial demonstrable benefits of such a policy if the State were to challenge the public consensus on this issue.

Thus the powerful statement of the democratic presumption at paragraph 132 that "the State should intervene only to prevent the occurrence of serious harms" has been converted into the requirement that "there would need to be substantial demonstrable benefits". Here not only has the democratic presumption been turned on its head, but the burden of proof has entirely shifted from the requirement that the State show that its interference is necessary to prevent the occurrence of serious harms to the rather feeble requirement that those who wish to exercise liberty must qualify for this freedom by showing that its exercise provides substantial demonstrable benefits. If this is to be the case liberty is meaningless and the presumption of liberal democracies is overthrown.

This is effectively what the HFEA report recommends. The illiberalism of this conclusion and the poverty of the arguments produced to defend and sustain it make it imperative that this report is not only rejected but that its conclusions and recommendations be recognised for what they are, namely an attempt to formalise the tyranny of the majority and to institutionalise contempt for the principles of liberal democracy.

J Med Ethics 2005;31:291-294.

doi: 10.1136/jme.2003.007526

Correspondence to: John Harris, Institute of Medicine, Law and Bioethics, School of Law, Williamson Building, University of Manchester, Oxford Road, Manchester M13 9PL;

john.m.harris@man.ac.uk

Received 27 November 2003

In revised form 1 December 2003

Accepted for publication 9 February 2004

\section{REFERENCES}

1 Human Fertilisation and Embryology Authority Sex selection: options for regulation. A report on the HFEA's 2002-03 review of sex selection including a discussion of legislative and regulatory options. London: HFEA, 2003.
2 Harding DW. Regulated hatred: an aspect of the work of Jane Austen. Scrutiny, 1940. The version I have used appears in Lodge D, eds. 20th Century Criticism. London: Longman, 1972:262.

3 "He led his regiment from behind-/, he found it less exciting. /but when away his regiment ran/ his place was at the for, O.../. W S Gilbert. The Gondoliers. Text in: Gilbert WS. The Savoy Operas.London:Macmillan, 1956:510.

4 Almost certainly different children but not necessarily so.

5 The Human Fertilisation and Embryology Act 1990 states: (Clause 13.5.) "A woman shall not be provided with treatment services unless account has been taken of the welfare of the child who may be born as a result of the treatment (including the need of that child for a father), and of any other child who may be affected by the birth." As it happens I think both procedures would maximise child welfare. I simply doubt the HFEA would agree.

6 I have argued this point at length elsewhere. See: The welfare of the child. Health Care Analysis 2000;8:27-34, and Justine Burley and John Harris, Human cloning and child welfare. J Med Ethics 1999;25: 108-14.

7 l owe this characterisation of the non-identity arguments to Julian Savulescu but from the horse's mouth you will find it in Derek Parfit's Reasons and Persons. Oxford: Clarendon Press, 1984: Chapter 16. See also Justine Burley and John Harris, Human cloning and child welfare. J Med Ethics 1999;25:108-14.

8 Robertson JA. Children of Choice. Princeton: Princeton University Press, 1994.

9 Dworkin R. Life's Dominion. London: Harper Collins, 1993.

10 Savulescu J. Deaf lesbians, designer disability and the future of medicine. $B M J$ 2002;325:771-3.

11 See my "Rights reproductive choice" in John Harris, Søren Holm, eds. The Future of Human Reproduction: Choice and Regulation. Oxford: Oxford University Press, 1998:5-37.

12 Parts of this section were published in "Podium", The Independent 27 November 2003:19. 